\title{
Temperature Effect on Space Charge Dynamics in XLPE Insulation
}

\author{
Y.L. Chong, G. Chen and Y.F.F. Ho \\ School of Electronics \& Computer Science \\ University of Southampton \\ Southampton, SO17 1BJ, UK
}

\begin{abstract}
This paper reports on space charge evolution in crosslinked polyethylene (XLPE) planar samples approximately $1.20 \mathrm{~mm}$ thick subjected to electric stress level of $30 \mathrm{kV} \mathrm{dc}_{\mathrm{dc}} / \mathrm{mm}$ at four temperatures $25,50,70$ and $90{ }^{\circ} \mathrm{C}$ for $24 \mathrm{~h}$. Space charge profiles in both asreceived and degassed samples were measured using the laser induced pressure pulse (LIPP) technique. The de threshold stresses at which space charge initiates are greatly affected by testing temperatures. The results suggest that testing temperature has numerous effects on space charge dynamics such as enhancement of ionic dissociation of polar crosslinked by-products, charge injection, charge mobility and electrical conductivity. Space charge distributions of very different nature were seen at lower temperatures when comparing the results of as-received samples with degassed samples. However at higher temperature, the space charge distribution took the same form, although of lower concentration in degassed samples. Space charge distributions are dominated by positive charge when tested at high temperatures regardless of sample treatment and positive charge propagation enhances as testing temperature increases. This can be a major cause of concern as positive charge propagation has been reported to be related to insulation breakdown.
\end{abstract}

Index Terms - Space charge, charge injection, crosslinked polyethylene insulation, heat treatment, ionization.

\section{INTRODUCTION}

SPACE charge in dielectric materials under dc electric stress has been extensively studied over the last few decades. However, most of such research work was conducted at room temperature while space charge dynamics in XLPE under dc electric stress at different temperatures has only received limited attention [1-7].

In a practical underground cable system, the operational temperature of underground cable is not constant, especially in countries where the climatic condition varies significantly during different times of the year. It has been reported that the temperature experienced by underground cable can go up to $90{ }^{\circ} \mathrm{C}$ [1]. As such, it becomes important to study and attempt to understand space charge dynamics in XLPE under various temperatures.

Manuscript received on 3 June 2005, in final form 25 July 2006.
This paper reports on space charge evolution in XLPE planar samples of approximately $1.2 \mathrm{~mm}$ thick subjected to electric stress level of $-30 \mathrm{kV}_{\mathrm{dc}} / \mathrm{mm}$ at temperatures $25,50,70$ and $90{ }^{\circ} \mathrm{C}$ for $24 \mathrm{~h}$. Space charge measurements in both asreceived and degassed samples were carried out using the laser induced pressure pulse (LIPP) method.

\section{EXPERIMENTAL DETAILS}

\subsection{LIPP SYSTEM}

The schematic diagram for the LIPP system used for this experiment is shown in Figure 1. This LIPP system can be used to measure space charge in XLPE insulation under dc and $50 \mathrm{~Hz}$ ac electric stresses [8]. However, only space charge profiles under dc electric stress were measured in this study. 


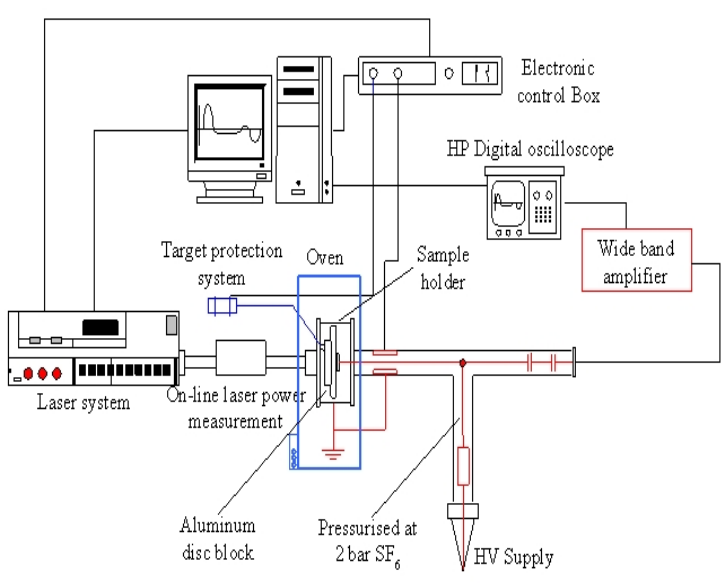

Figure 1. LIPP system setup.

Details of the technique and the principle behind its operation can be found in numerous publications [8-18]. In short, a very short (5 ns) laser pulse irradiates the front electrode (target) of the sample producing an acoustic pressure pulse due to the rapid thermal expansion of the target material. The dielectric is rapidly compressed by the leading edge of the pressure wave and then gradually relaxes back to its original state [19]. Under the effect of this mechanical disturbance, two effects are observed: any charge attached to the local atomic structure is displaced; and the relative permittivity of the sample is modified due to the variation in dipole and charge concentrations. These effects create a change in the induced charges on the electrodes, which produce a current in an external circuit. Through the evolution of the current, information on the space charge distribution within the XLPE can be calculated [20]:

$\rho(x)=f\left(I_{\text {space }}, I_{\text {cal }}\right)=\frac{I_{\text {space }}(x, t)}{I_{c a l}(0, t)} \frac{P_{0}}{P_{x}} \frac{\varepsilon_{0} \varepsilon_{r} E_{\text {cal }}}{v_{\text {sa }} \tau(x)}$

where: $\rho(x, t)=$ charge density at location $x$

$I_{\text {space }}(x, t)=$ current at location $x$

$I_{\text {cal }}(0, t)=$ calibration current at target interface

interface

$P_{0}=$ amplitude of pressure wave at target

$P_{x}=$ amplitude of pressure wave at location $x$

$\varepsilon_{o}=$ permittivity in free space

$\varepsilon_{r}=$ relative permittivity

$E_{c a l}=$ electric field used for calibration

$v_{s a}=$ velocity of sound in sample

$\tau(x)=$ width of pressure wave at location $\mathrm{x}$

A typical output signal of the LIPP is shown in Figure 2.

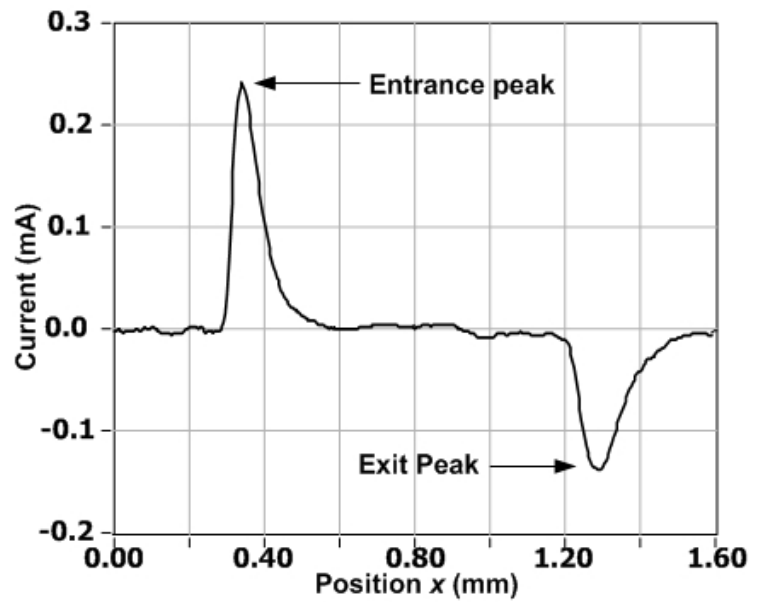

Figure 2. Typical LIPP output signal.

The entrance peak and the exit peak in Figure 2 are the induced charges caused by the applied voltage. Their amplitude, under no space charge condition, should be proportional to the applied electric stress.

This LIPP system has numerous improvements from the conventional LIPP system, such as computer-controlled automation [21] and target protection system comprising of target cooling liquid (our choice of liquid is silicon oil) and aluminum disc block which acts as a target for the laser [22].

It has been reported that the efficiency of laser absorption in the semi-con target surface will degrade after experiencing more than 40 laser shots [8]. In an attempt to prevent any error caused by target degradation, cylinder of aluminium block was placed in front of the front semi-con electrode to act as the laser target, such that measurement errors created by target ablation can be minimised. Figure 3 illustrates a detailed sample arrangement with the aluminum disc block.

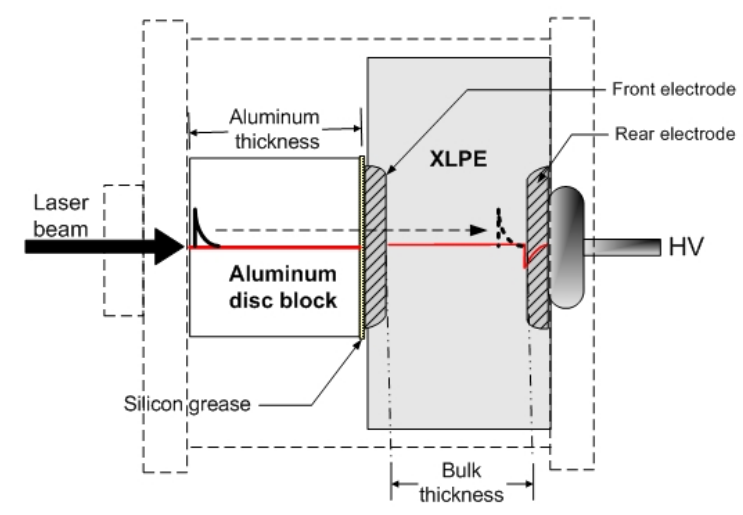

Figure 3. Detailed view of sample holder incorporating aluminum disc block.

It should be noted that the thickness of the aluminium block is critical; too thin will result in interfering reflected waves, while too thick will result in reduced spatial resolution. The aluminium plate used in the present study is $1.98 \mathrm{~mm}$ thick. A detailed review of this can be found in [22]. 


\subsection{SAMPLES DETAILS}

The samples used were made using cable graded XLPE material (Borealis XL4201S). The semi-con electrodes were made from XLPE loaded with carbon black (LEO592).

Firstly, the insulating bulk of approximately $1.6 \mathrm{~mm}$ and semi-con electrodes of $0.2 \mathrm{~mm}$ thick were made, uncrosslinked, by hot pressing the respective pellets at about $150{ }^{\circ} \mathrm{C}$. Next, both the front and the rear electrodes were hot pressed into plaque sample at about $200{ }^{\circ} \mathrm{C}$ for 10 minutes to ensure crosslinking. The samples were subsequently quenched to room temperature with cold water $\left(<10{ }^{\circ} \mathrm{C}\right)$ running through the hot press. The resulting bulk insulation between the two semi-con electrodes is expected to be roughly $1.2 \mathrm{~mm}$ thick.

All degassing was done in a vacuum at $90{ }^{\circ} \mathrm{C}$ for $48 \mathrm{~h}$. The samples were then left to cool at room temperature for 15 mins. Details of the samples and experimental conditions are shown in Table 1.

Table 1. Sample details and experimental conditions.

\begin{tabular}{|c|c|c|c|}
\hline Sample & $\begin{array}{c}\text { Sample } \\
\text { treatment }\end{array}$ & $\begin{array}{c}\text { Bulk } \\
\text { thickness }\end{array}$ & $\begin{array}{c}\text { Testing } \\
\text { temperature }\end{array}$ \\
\hline $\mathrm{A}$ & As-received & $1.21 \mathrm{~mm}$ & $25^{\circ} \mathrm{C}$ \\
\hline $\mathrm{B}$ & As-received & $1.17 \mathrm{~mm}$ & $50^{\circ} \mathrm{C}$ \\
\hline $\mathrm{C}$ & As-received & $1.25 \mathrm{~mm}$ & $70{ }^{\circ} \mathrm{C}$ \\
\hline $\mathrm{D}$ & As-received & $1.26 \mathrm{~mm}$ & $90{ }^{\circ} \mathrm{C}$ \\
\hline $\mathrm{E}$ & Degassed & $1.12 \mathrm{~mm}$ & $25^{\circ} \mathrm{C}$ \\
\hline $\mathrm{F}$ & Degassed & $1.19 \mathrm{~mm}$ & $50^{\circ} \mathrm{C}$ \\
\hline $\mathrm{G}$ & Degassed & $1.26 \mathrm{~mm}$ & $70{ }^{\circ} \mathrm{C}$ \\
\hline $\mathrm{H}$ & Degassed & $1.20 \mathrm{~mm}$ & $90{ }^{\circ} \mathrm{C}$ \\
\hline
\end{tabular}

\subsection{EXPERIMENTAL PROTOCOLS}

The samples were loaded in the sample holder and then placed inside an oven. The temperature in the oven is controlled by a temperature controller. All samples were held at the set temperature for $1 \mathrm{~h}$ before any space charge measurements were taken. This is necessary to ensure that the samples have reached thermal equilibrium as temperature affects the pressure pulse induced by the laser and also the velocity of the acoustic pulse as it transverse across the sample $[17,18]$.

The space charge experiment consists of two parts; the step voltage test and the dc ageing test.

\subsubsection{STEP VOLTAGE TEST}

First, a step voltage test was conducted to determine the voltage level at which space charge effect initiates. This is referred to as the threshold voltage or simply $\mathrm{V}_{\text {th }}$ of the sample. Voltages were applied from 0 to approximately 35 $\mathrm{kV}$, with a voltage step of $5 \mathrm{kV}$ every 5 secs. The entrance peak of the space charge signal was then plotted against the applied voltage.

\subsubsection{AGEING TEST}

Immediately following the step voltage test, the samples were stressed under dc voltage conditions at the stress level for a duration of $24 \mathrm{~h}$ at temperature shown in Table 1. The space charge profiles of each sample with applied voltage (herein known as volt-on profiles) and shortly after voltage removal (herein known as volt-off profiles) were measured at various times during the ageing period.

While degassing of as-received samples is inevitable during the measurement at high temperature, however such effect is assumed to be limited and hence not taken into account.

Minor changes in the morphological structures of the samples as a result of difference testing temperatures is also ignored as it has been demonstrated [23] that such effect on space charge is insignificant.

\section{RESULTS AND DISCUSSION}

\subsection{STEP VOLTAGE TEST}

In this experiment, only the magnitude of the entrance peaks (anode) of the space charge signal is plotted against the applied voltage. This is because the magnitude of the noise will be of similar order as that of the actual signal due to the relatively poor signal-to-noise ratio of the exit peak when the applied voltage is small. As such, any data extracted from the exit peak of the space charge signal, when the applied voltage is small, may be questionable.

The generation of pressure pulse is a result of rapid heating of the target surface. Due to this, the temperature of the target has a definitive effect on the magnitude of the entrance peak. Hence, in order to have a better comparison of the step voltage results, the magnitude of the entrance peak of each sample is normalised with respect to the final value obtained during the step voltage test.

\subsubsection{AS-RECEIVED SAMPLES (SAMPLES A TO D)}

The normalised entrance peaks of the space charge signal are plotted against the applied voltage of the as-received samples are shown in Figure 4.

In the absence of space charge, the magnitude of the entrance peak of the LIPP signal should have a linear relationship with the applied voltage. This is represented by the dotted line shown in Figure 4 


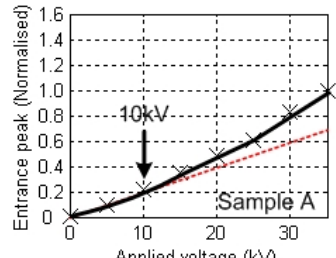

Applied voltage $(\mathrm{kV})$
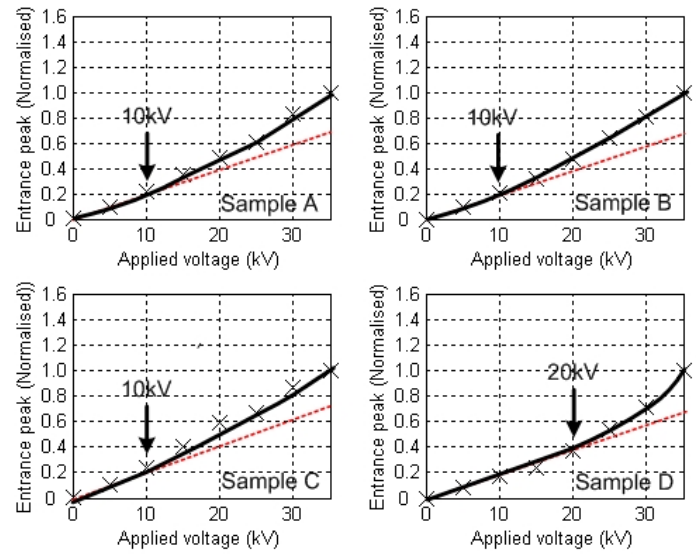

Figure 4. Normalised entrance peak (anode) magnitudes of the LIPP current against the applied voltage of as-received samples.

Any deviation from the dotted line indicates the presence of space charge. Figure 4 suggests that the threshold voltage at which space charge initiates are roughly $10 \mathrm{kV}$ for samples A to $\mathrm{C}$ and $20 \mathrm{kV}$ for sample $\mathrm{D}$. Positive deviation of the curves from their respective dotted line suggests electric stress enhancement of at the interface. Stress enhancement at the interface is normally caused by heterocharge accumulation in the vicinity of the interface. For samples A to D, negative charge is expected to have accumulated near the anode when the applied voltage is higher than their individual threshold value.

The by-products generated from crosslinking include acetophenone, alpha methyl styrene, cumyl alcohol and water. It has been reported that acetophenone generates ionic charges in XLPE when coexist with water [24]. $\quad$ The formation of negative charge near the anode of samples A to D is believed to be caused by electric stress assisted ionic dissociation of crosslinked by-products. This is consistent with the results reported in [23] that space charge in asreceived samples is dominanted by heterocharge.

It is also possible that charge injected from the electrodes migrated towards the opposite electrodes. However, it is unlikely in the present case as the time for the injected charge to travel across the sample could be several minutes [25].

For ionic dissociation to occur, energy is required to break the bond holding the ionic pairs together. In the present case the cross-linked by-products (neutral) could be considered as being in chemical equilibrium with their ionic components. The energy gained from the electric field may be sufficient to separate ions by a Debye length for which the ions essentially become independent. On the other hand, energy is also required to transport the injected charge to the opposite electrodes. From the above experimental setup, there are two sources of energy: electrical from the applied voltage and thermal from the heating. Bearing this in mind, one would expect the threshold voltage of sample $\mathrm{D}$ to be the lowest considering it has the highest thermal energy which contradicts the results of the step voltage test.
In order to explain this, the space charge profile of sample $\mathrm{D}$ with an applied voltage of $20 \mathrm{kV}$ was further examined.

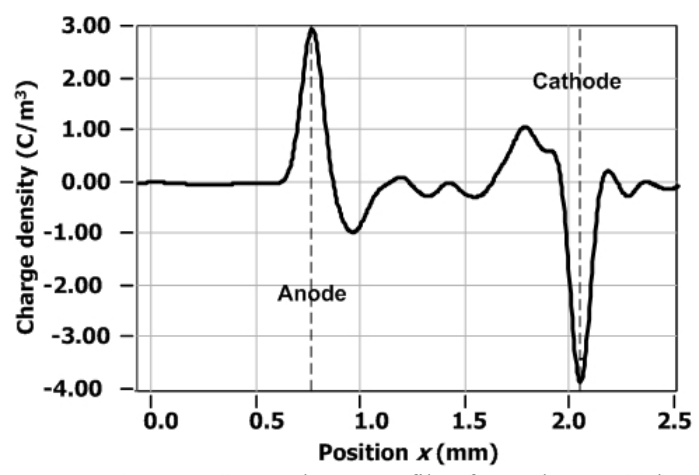

Figure 5. Space charge profile of sample D at $20 \mathrm{kV}$.

Figure 5 shows the space charge profile of sample D during the $20 \mathrm{kV}$ stage of the step voltage test. Heterocharges can be clearly seen in the vicinity of both electrodes. As mentioned earlier, the formation of heterocharges normally enhances the interfacial stress. However, this is not reflected on the step voltage experiment. One possible explanation is that the positive heterocharge near the cathode is significantly larger than the negative charge adjacent to the anode, masking off its effect on the interfacial stress at the anode.

To confirm this, the electric field distribution, $E(x)$, across the sample was computed based on Poisson's equation:

$$
\frac{d E(x)}{d x}=\frac{\rho(x)}{\varepsilon_{0} \varepsilon_{r}} d x, \quad 0<\mathrm{x}<\mathrm{d}
$$

where $\rho(x)$ is the charge density at $x, \varepsilon_{0}$ the vacuum permittivity, $\varepsilon_{\mathrm{r}}$ the relative permittivity of XLPE and $\mathrm{d}$ the sample thickness.

The electric field distribution across sample D is shown in Figure 6.

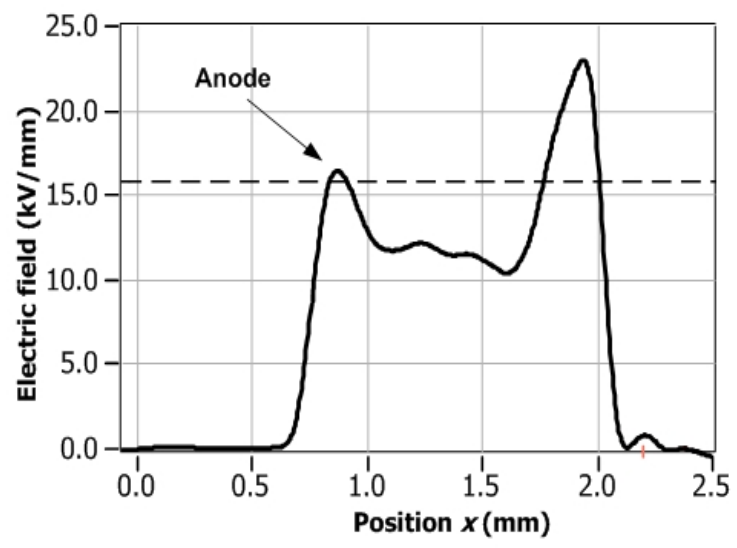

Figure 6. Electric field distribution across sample D at $20 \mathrm{kV}$. 
The approximate average electric stress across the sample, that is, the stress across the sample if there is no space charge inside the sample is represented by the dotted line. It can be seen that the actual electric stress at the anode, as indicated by an arrow, is almost the same as the average stress despite the presence of space charge which clearly affects the electric field across the bulk and at the cathode. This suggests that the results from the step voltage test should not be used explicitly but to be complemented with space charge profiles and electric field distributions whenever possible.

Although there is no calibration signal for sample $\mathrm{D}$, the space charge signal during the $5 \mathrm{kV}$ step was used as a calibration for the above analysis. It should be pointed out that this signal has space charge accumulation and very poor signal-to-noise ratio (due to the rather low electric stress and high testing temperature). As a result of these factors, the result in Figure 6 may not be totally correct.

Notwithstanding the possible error of Figure 6, it is good enough to illustrate that the presence of space charge may not necessarily leads to enhancement of the interfacial stress.

Careful examination of the all space charge profiles and electric field distributions of the step voltage test revealed that only samples A and B truly reflect the threshold voltage suggested by the test. Sample C, however, indicates space charge accumulation at applied voltage of $10 \mathrm{kV}$ while in the case of sample $\mathrm{D}$, the threshold voltage is less than $5 \mathrm{kV}$. This is probably because the amount of thermal energy gained by the samples A and B is not enough to cause any difference in the threshold voltage. At $70{ }^{\circ} \mathrm{C}$, the amount of thermal energy gained, together with the energy from the applied field, is probably big enough to break the holding bonds even at a low applied voltage of $10 \mathrm{kV}$. Not surprisingly, this effect is even more pronounced in sample $\mathrm{D}$ tested at $90{ }^{\circ} \mathrm{C}$.

It is important to highlight the significance of the step voltage test results of sample $\mathrm{D}$. As the threshold voltage was less than $5 \mathrm{kV}$, there is a problem with choosing the reference signal for calibration purpose. This is because even at $5 \mathrm{kV}$, the poor signal-to-noise ratio of the output profile is barely suitable for calibration purpose; let alone lower than $5 \mathrm{kV}$. On the other hand, if the applied voltage was higher than $5 \mathrm{kV}$, space charge would have already built up.

The accumulated space charge in a sample $\rho_{\text {accumulated }}(x)$ of can be calculated using

$$
\rho_{\text {accumulated }}(x)=\rho_{\text {volt-on }}(x)-\rho_{\text {electrodes }}(x)
$$

where:

$\rho_{\text {volt-on }}(x)=$ volt-on space charge profile with charge

$\rho_{\text {electrodes }}(x)=$ charge induced by the applied voltage on the electrode
Assuming that the charge in the sample is trapped reasonably deep such that there is no fast charge, $\rho_{\text {accumulated }}(x)$ will be equal to $\rho_{\text {volt-off }}(x)$. By substituting $\rho_{\text {volt-off }}(x)$ for $\rho_{\text {accumulated }}(x)$ and rearranging equation 3 , one has

$$
\rho_{\text {electrodes }}(x)=\rho_{\text {volt-on }}(x)-\rho_{\text {volt-off }}(x)
$$

Hence, under no fast charge condition, $\rho_{\text {electrodes }}(x)$ can be calculated using equation (4). This space charge profile can, therefore, be used as a reference signal for calibration purpose. It must be stressed that this is true if and only if

$$
\rho_{\text {fast }}(x)=\rho_{\text {accumulated }}(x)-\rho_{\text {volt-off }}(x) \approx 0
$$

where $\rho_{\text {fast }}(x)$ is the fast charge

A few of points regarding the concept of space charges and fast charges as used in this paper need to be highlighted. Firstly, a finite time interval is needed between the removal of applied voltage till the measurement of $\rho_{\text {volt-off }}(x)$. The time interval for such measurements is fixed at $4-5 \mathrm{~s}$ for this experiment. As such fast charges, in the context of this paper, are charges that liberate themselves during this 4-5 seconds window.

Secondly, fast charges are charges that have sufficient energy in them to surmount the depth of the traps that they were trapped upon removal of applied voltage. A charge with higher energy, enabling it to liberate itself from a trap with a deep depth is considered a fast charge. On the other hand, a charge trapped in a relatively shallower trap but does not have enough energy to surmount the trap is not considered as fast charge. In other words, the depth of the trap alone has no direct bearing on whether a charge is considered as fast charge or not.

Lastly, the LIPP technique utilises propagation of acoustic waves acting as a virtual probe sensitive to charges for the measurement of space charge. Hence, the charges that are transported from end of the electrode to the other at a speed faster than that of acoustic wave travelling in the same media (in the case of XLPE at room temperature is approximately $2000 \mathrm{~m} / \mathrm{s}$ ), will not be detected by the measurement technique. Such charges, although technically should be considered as space charge, will not be taken into account in this paper.

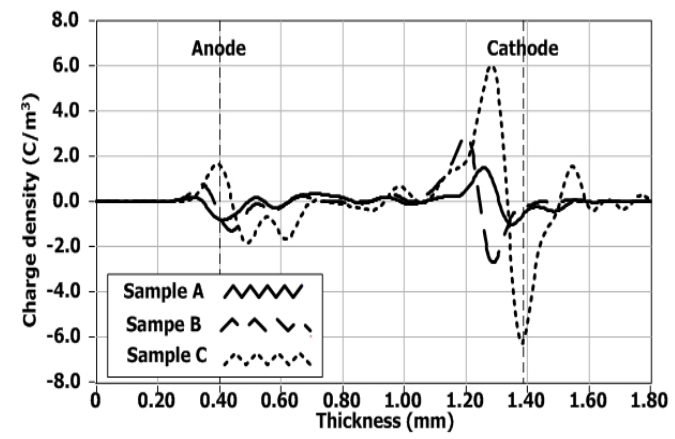

Figure 7. Fast charge in samples A to $\mathrm{C}$ immediately after step voltage test. 
Throughout the step voltage test, no volt-off space charge profile was measured until the final stress level of each sample was obtained. Based on $\rho_{\text {electrodes }}, \rho_{\text {volt-on }}$ and $\rho_{\text {volt-off }}$ space charge profiles immediately after the step voltage test, accumulated charge profile ( $\left.\rho_{\text {accumulated }}\right)$ can be calculated using equation 3 , while fast charge $\left(\rho_{\text {fast }}\right)$, can be calculated using equation 5. The fast charge profiles of samples $\mathrm{A}$ to $\mathrm{C}$ were computed and shown in Figure 7.

The fast charge of sample D cannot be computed because all the space charge profiles measured have charge accumulation, in other words, there is not a $\rho_{\text {electrodes. }}$. Nonetheless, from Figure 7, it can be seen that the higher the testing temperature, the more fast charge present in the sample. This is probably due to the increase in charge's mobility with temperature as reported in $[1,7,17]$. This increase in charge's mobility is probably attributed to the fact that charges in sample B have higher energy than that in sample A. Therefore, more of these charges will have enough energy to be detrapped shortly after the applied voltage removed. This effect is even more pronounced in sample C which is tested at even higher temperature.

\subsubsection{DEGASSED SAMPLES (SAMPLES E TO H)}

The step voltage results of the degassed samples are shown in Figure 8.
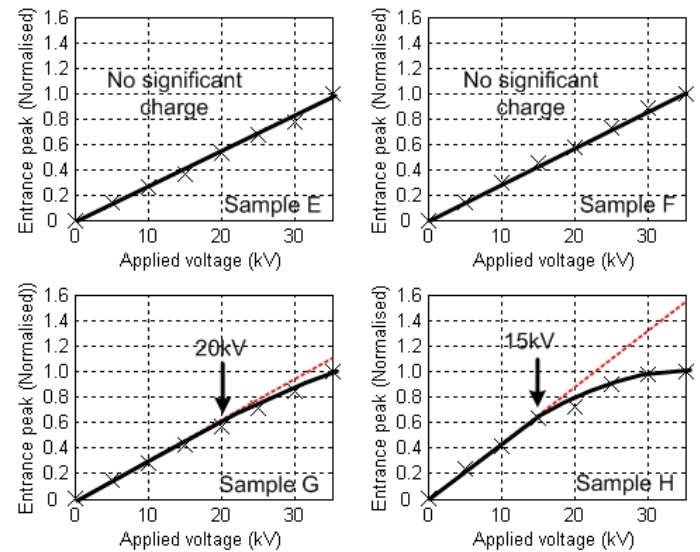

Figure 8. Normalised entrance peak (anode) magnitudes of the LIPP current against the applied voltage of degassed samples.

As seen in Figure 8, the relationship between the entrance peak magnitude and the applied voltage of the samples $E$ and $\mathrm{F}$ appears to be linear. This suggests that no significant charge has been formed adjacent to the anode in the degassed sample during the step voltage test up to $50{ }^{\circ} \mathrm{C}$. This is probably due to the reduction in crosslink by-products from degassing which in turn reduces the amount of ionic pairs that can be dissociated by the applied electric field.

In the case of samples $G$ and $H$, the magnitude of the entrance peak against the applied stress deviates negatively from the dotted trend line. This indicates that homocharge has been formed close to the anode. This is believed to be caused by charge injected from the anode to the insulation. By comparing the results of all the degassed samples, it is evident that the threshold stress of the homocharge formation decreased from above $35 \mathrm{kV}$ to $15 \mathrm{kV}$ as the testing temperature was increased from 25 to $90{ }^{\circ} \mathrm{C}$. This suggests that charge injection is enhanced by high temperature.

\subsection{AGEING TEST}

\subsubsection{AS-RECEIVED SAMPLES}

The volt-off space charge profiles taken at various times and the corresponding charge integral of sample A were shown in Figure 9. The charge integral can be calculated using equation 6 . The charge integrals were calculated across the bulk of the sample and sub-divided into positive and negative charges with the sum being the net. It should be noted that the charge integral does not include the induced charge on the electrodes.

$\mathrm{Q}(t)=\int_{0}^{d} \rho(x, t) \mathrm{S} . d x, \quad 0<\mathrm{x}<\mathrm{d}$

where $\mathrm{S}$ is the electrode area.The volt-off space charge profiles show trapped charge, since this charge remains in the sample after the applied voltage has been removed.

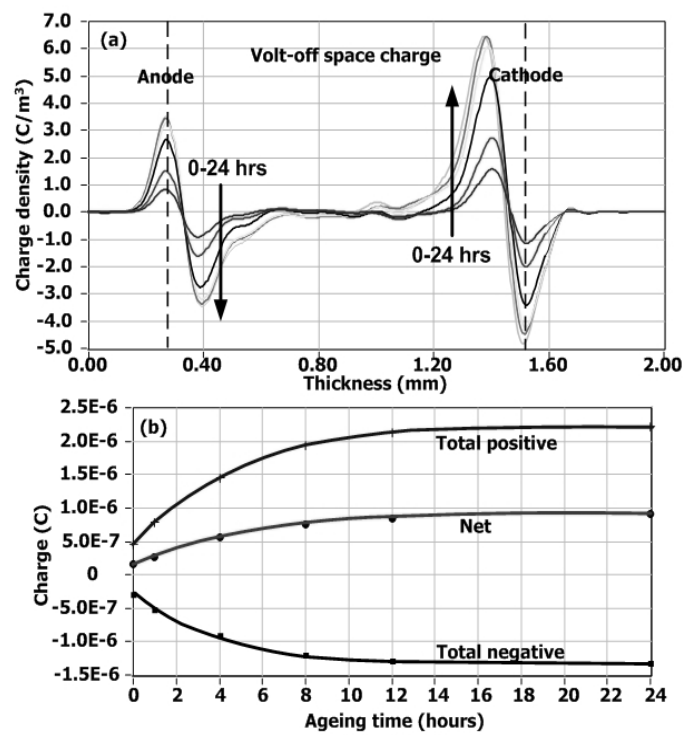

Figure 9. (a) Volt-off space charge profiles and (b) charge integrals of sample A.

As seen in the volt-off space charge profiles, heterocharges were trapped in the vicinity of both electrodes. These heterocharges can be seen even at 0 hour (i.e. immediately after step voltage test) and increased with ageing time. This is in agreement with the step voltage result. It should be pointed out that ageing time, in this paper, refers to the duration which the sample is under the applied voltage.

From the charge integral plot, it can be seen that the rate at which space charge was build up reduces with ageing time. This is probably because as the amount of heterocharges increased, the stress at semicon/insulation interfaces also increased. This increase in the interfacial stress enhanced charge injection which neutralised some of the heterocharges which had accumulated.

Figure 10 shows the fast charge profiles in sample A, which were computed using equation 5 , and their integrals over 24 
hours of ageing. Unlike the charges in the volt-off space charge profiles which are trapped in the sample, fast charges are charges which disappeared almost immediately after the removal of the applied voltage. A quick comparison between the volt-off space charge profiles and the fast charge profiles shows clearly that the amount of fast charge is significantly less than that of the volt-off space charge, particularly the negative charge adjacent to the anode. This suggests that most of the charges in the sample did not have enough energy to overcome the trap depth.
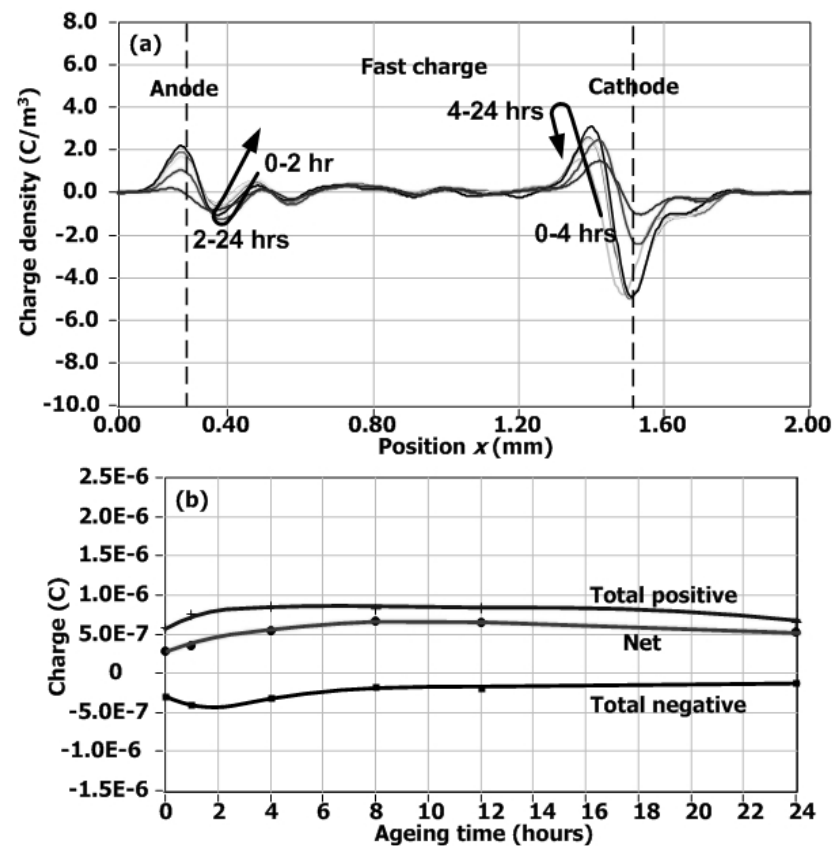

Figure 10. (a) Fast charge profiles and (b) charge integrals of sample A.

Comparing the charge integrals of the trapped charge and the fast charge, it can be seen that the amount of space charge trapped (i.e. volt-off space charge) in sample A increased with ageing time, while the amount of fast charge increased during the early stages of the ageing period, but reduced after about 2 $\mathrm{h}$ in the case of negative charge and 4 hours for positive charge.

It has been reported that space charge trapped in samples of LDPE or indeed XLPE tends to decay at a slower rate when the samples have been aged under dc [26-28] or ac [29-32] electric stress for longer duration or higher stress level as compared to one aged for a shorter duration or lower stress level when short-circuited. Bearing this in mind, the reduction of fast charge in sample A could be interpreted as indicating formation of deep traps being accompanied by reduction of shallow ones as a result of dc ageing.

Figure 11 illustrates the volt-off space charge profiles of sample B and its integral.
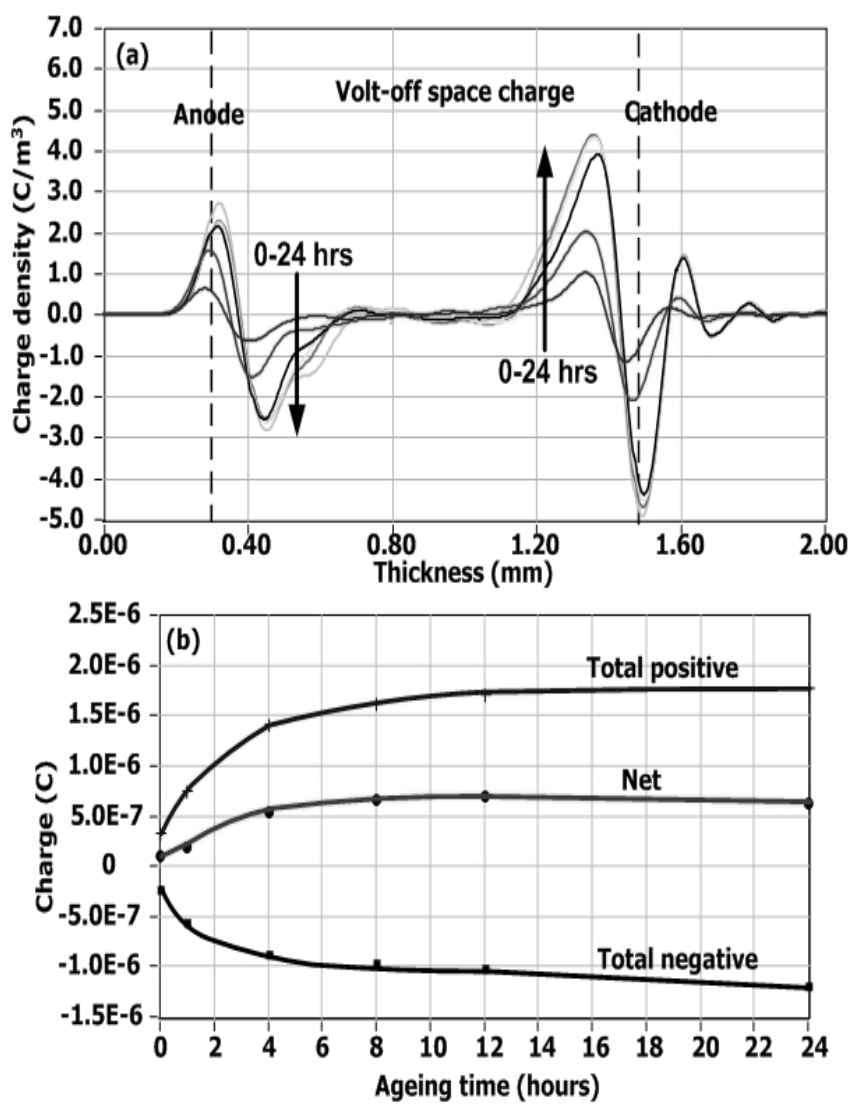

Figure 11. (a) Volt-off space charge profiles and (b) charge integrals of sample B.

The general distribution of the charge trapped in the sample B is similar to that of sample A. As in the case of sample A, the amount of trapped heterocharges in sample B also increased with ageing time but the amount is comparatively smaller. This is probably due to the increase in testing temperature, which would result in a number of implications. Firstly, the increase in temperature may result in enhancement of charge injection at the electrodes, which in turn neutralised the heterocharges. Secondly, higher temperature causes electric conductivity to increase. As such it will be more difficult for sample B to trap charge as they are moving at a faster speed. Thirdly, as the temperature in sample B is higher than sample A, the charges in the former will have higher energy and, therefore, may possess enough energy to surmount certain shallow traps almost immediately after the removal of the voltage.

Figure 12, which shows the fast charge profiles in sample B and their integrals, indicates relatively large amount of fast charge when compared to sample A. This partially supports the earlier argument of more charge having enough energy to surmount the trap depth as a result of higher energy. 

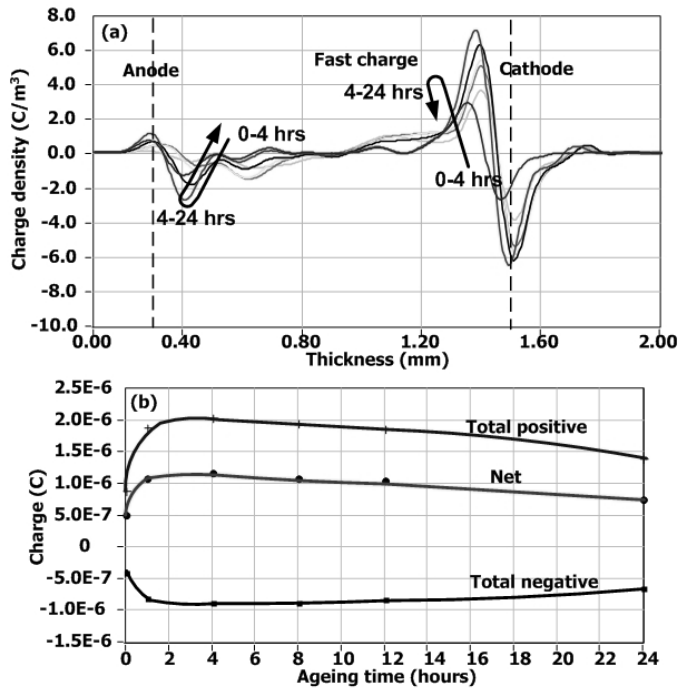

Figure 12. Fast charge profiles and charge integrals of sample B.

It is noted that the rate of fast charge accumulation in sample B increases rapidly during the first 2 hours of the ageing but reduces steadily after 4 hours of ageing. This rapid increase followed by gradual decrease of fast charge, although less pronounced, was also seen in sample A. Therefore, it is believed that the charge generating mechanism of the sample B is basically the same as sample A, only accelerated and enhanced by the increase in temperature. It is also interesting to note that, the fast charge profiles were dominated by positive charge and its magnitude is comparable to the positive trapped charge.

Figure 13 shows the volt-off space charge profiles and its integral of sample $\mathrm{C}$ and Figure 14 shows the corresponding fast charge profiles and integral.

From these Figures, it can be seen that sample $\mathrm{C}$ has significantly less trapped and fast charge compared to samples A and B. Furthermore, like in the case of samples A and B, the amount of fast charge reduces with ageing times. These changes are probably due to the increase in testing temperature, relative to samples A and B.
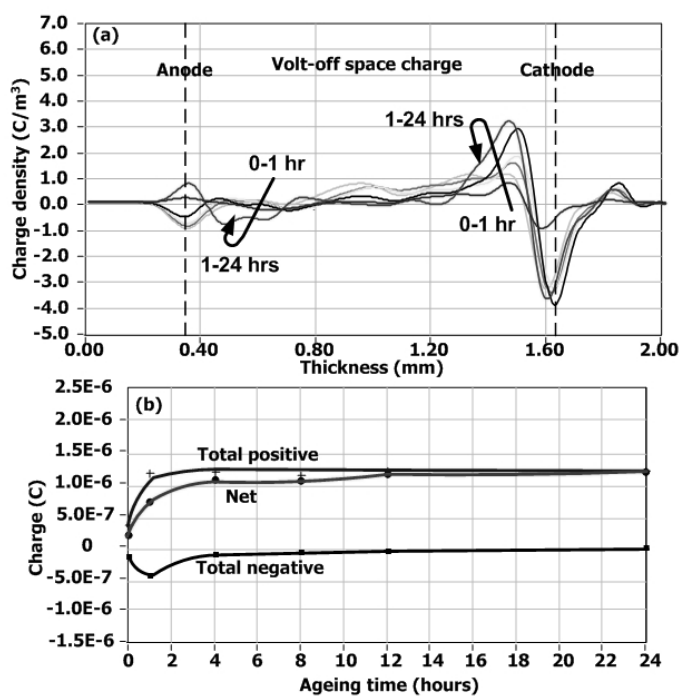

Figure 13. (a) Volt-off space charge profiles and (b) charge integrals of sample C.

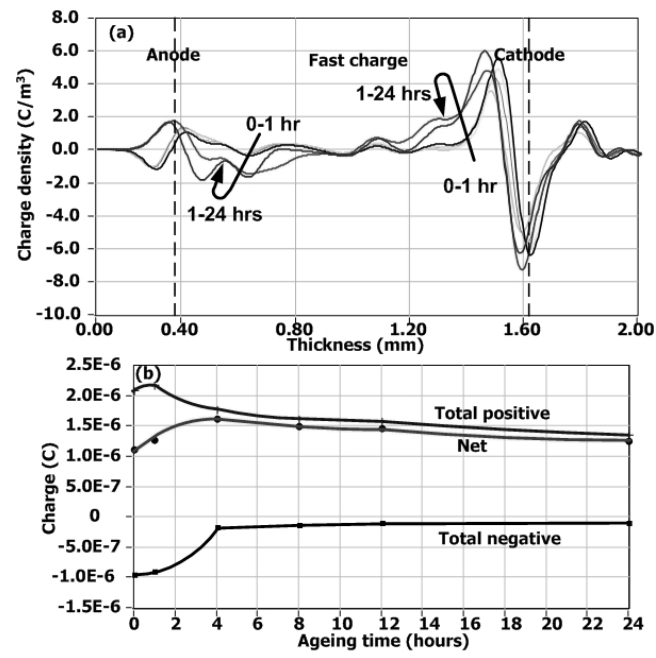

Figure 14. (a) Fast charge profiles and (b) charge integrals of sample C.

Comparing the results of samples $\mathrm{A}$ to $\mathrm{C}$, it can be concluded that, for this combination of electrode and insulation materials, positive trapped charge dominates the space charge dynamics under high temperature dc ageing.

\subsubsection{DEGASSED SAMPLES}

The volt-off space charge profiles of sample E and their integral can be seen in Figure 15.

The formation of homocharge in the vicinity of both electrodes is believed to be caused by charge injection from the electrodes into the insulating material. As mentioned earlier, crosslinked by-products can be dissociated into ionic pairs under the influence of electric field. Sample E, being strongly degassed at $90{ }^{\circ} \mathrm{C}$ for $48 \mathrm{~h}$ will have its volatile crosslinked by-products largely removed [33].

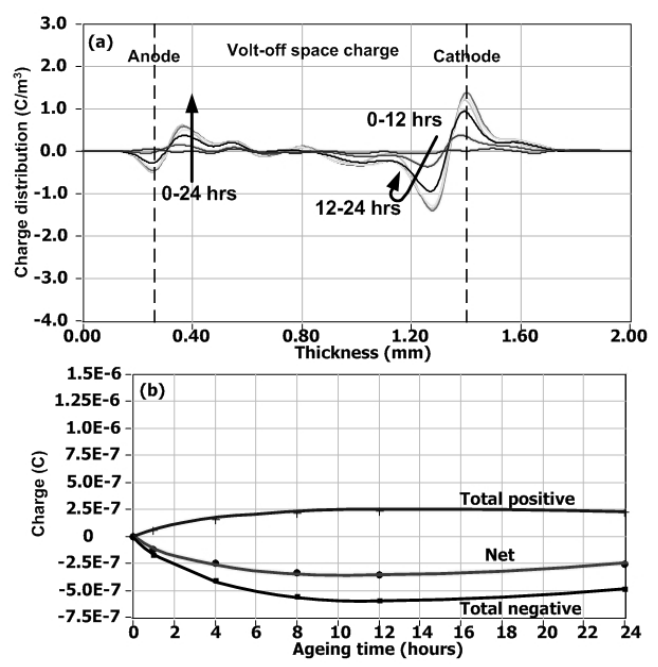

Figure 15. (a) Volt-off space charge profiles and (b) charge integrals of sample E.

As mentioned earlier, the two agents of crosslinked byproducts- acetophenone and water generates ionic charges when coexist. There are also reports that acetophenone 
increase conductivity such that carrier transport becomes accelerated [34-39]. The combination of these two effects causes the ionic charges generated to be more easily transported to electrode of the opposite polarity forming heterocharge.
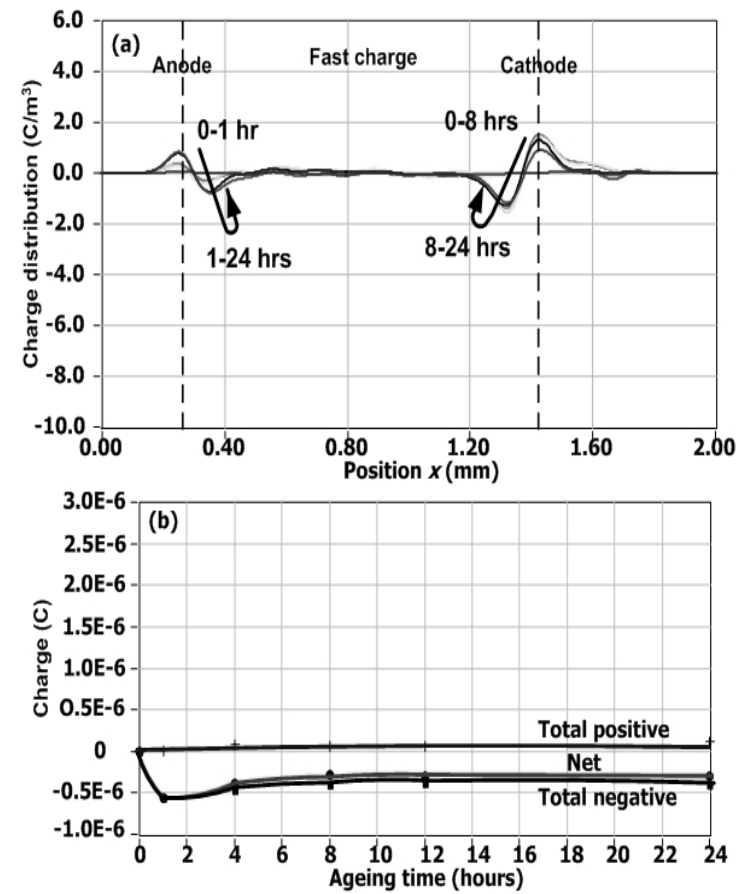

Figure 16. (a) Fast charge profiles and (b) charge integrals of sample E.

On the other hand, due to the lack of crosslinked byproducts after strong degassing, there will be significantly less heterocharge formation. Furthermore, any charge injected will more likely be trapped in the vicinity of the electrodes, forming homocharge, as opposed to being transported to opposite end since the conductivity is reduced. These are the main reasons homocharge is usually dominant in pure $\mathrm{PE}$ or XLPE samples that have been strongly degassed.

Figure 16 shows the fast charge profiles and charge integral of sample E. As seen from the fast charge profiles, only negative fast charge can be seen in the sample.

Evidently, from both the trapped and fast charge integrals, negative charge seems to be more dominant than positive charge. In the absence of ionic dissociation of crosslinked byproducts, most of the charge, both trapped and fast, in the sample originates from charge injected across the insulation/semicon electrodes interfaces. Bearing this in mind and looking at the negative fast charge in the vicinity of the anode, suggests that, at $25^{\circ} \mathrm{C}$, negative charge is more mobile than positive charge and more readily to be transported from the cathode to the anode. Careful observation of the volt-off space charge profile in Figure 15, which indicates that negative charge is more widely distributed in the bulk as compared to positive charge, further supports the above statement.

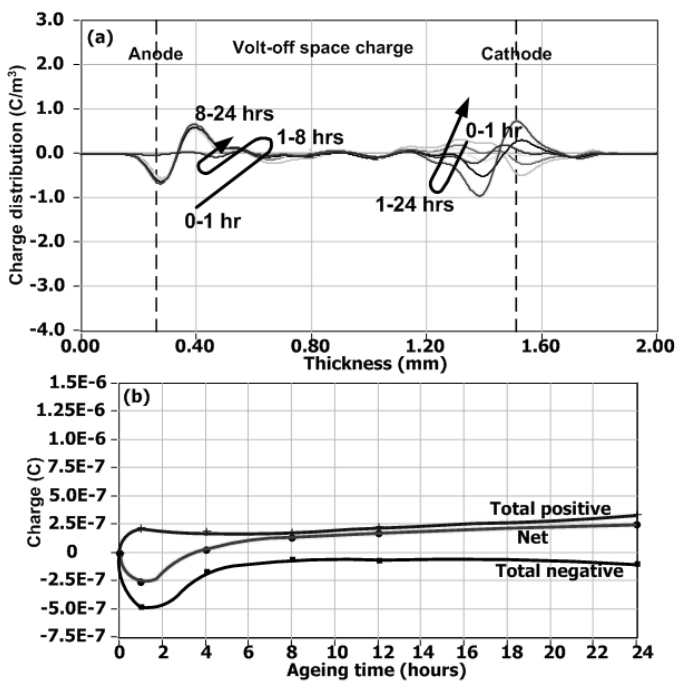

Figure 17. (a) Volt-off charge profiles and (b) charge integrals of sample F.

With reference to Figure 17, which shows the volt-off space charge profiles and charge integral of sample $\mathrm{F}$, a rapid increase in homocharge accumulation adjacent to both electrodes can be observed after 1 hour of ageing. Beyond 1 hour, the negative charge at the cathode started to decrease while the positive charge near the anode remained reasonably stable throughout the ageing experiment. It was also noted that all the negative charge in the vicinity of the cathode disappeared after about 4 hours and was replaced by a small amount of positive charge.

The origin of the positive charge may be attributed to the increase in charge injection and charge mobility as a result of increase in temperature, causing more positive charge to be injected, transported and eventually trapped at the cathode.

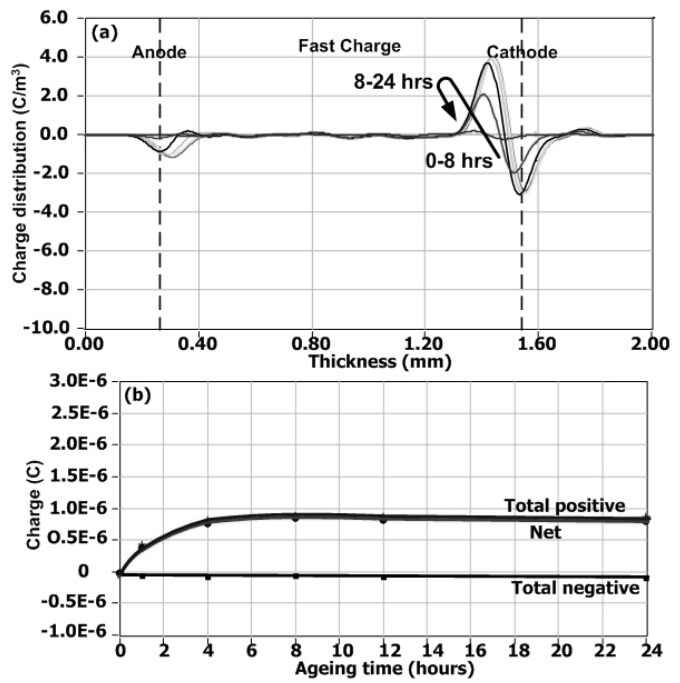

Figure 18. (a) Fast charge profiles and (b) charge integrals of sample F. 
Only positive fast charge can be seen in sample $F$ as shown in Figure 18. No fast charge was present at 0 hour or immediately after the step voltage test. This was followed by an increase in positive fast charge in the vicinity of the cathode during the first 8 hours before it reduces slightly.

Boudou et al reported that an enhancement of positive charge de-trapping and negative charge injection occurs at about $45^{\circ} \mathrm{C}$ in virgin LDPE [2]. Although the material used in this present study is XLPE, both are still polyethylene-based materials; the only difference being one was crosslinked. However, the electrical properties of polymer were reported to remain relatively unaltered by the crosslinking process [40]. Indeed, studies $[41,42]$ have shown that strongly degassed XLPE exhibits similar space charge characteristics as LDPE.

Taking all these into consideration and that the polarity of the applied voltage was opposite plus there have been reports which showed that polarity reversal resulted in mirror image space charge distributions $[4,17,43]$, therefore, it can be said that there is agreement between the results reported by Boudou et al and those in the present study.

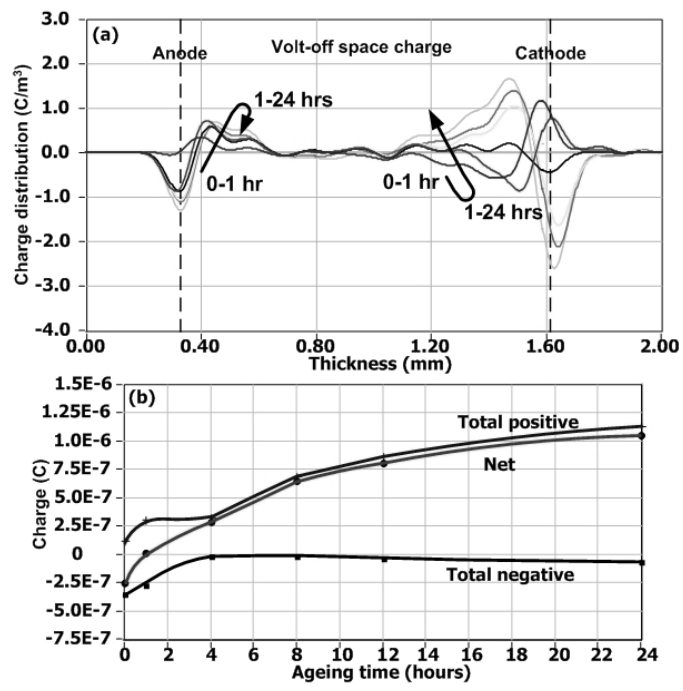

Figure 19. (a) Volt-off charge profiles and (b) charge integrals of sample G.

The volt-off space charge profiles of sample G, shown in Figure 19 indicates homocharges accumulation near both electrodes at 0 hour. This confirmed the results obtained from the step voltage test, which suggested accumulation of positive charge at the anode when the applied voltage exceeds $20 \mathrm{kV}$. This is probably due to the enhanced injection from the electrode as a result of increase in temperature. These homocharges continued to increase after 1 hour of ageing.

The space charge dynamics of the trapped charge in sample G seemed to follow the trend of sample $F$, the only difference being the effect was pronounced. This is probably because all the possible causes used to explain space charge formation in sample F can be accelerated and enhanced with higher temperature.

With reference to Figure 20, which shows the volt-off space charge profiles and charge integrals of sample $\mathrm{H}$, although there appeared to be a slight amount of charge in the sample at
0 hour, it was of the same magnitude as the noise. This relatively poor signal-to-noise ratio is probably due to the change in acoustic properties of the XLPE sample. Due to this, the observed signal may not be the actual charge but an artefact of the LIPP system.

Similar to samples E to G, homocharges were seen trapped near the electrodes of the sample $\mathrm{H}$ after 1 hour of ageing. However, at the $4^{\text {th }} \mathrm{h}$, relatively large amount of positive charge were seen trapped in the vicinity of the cathode and remained reasonably stable during the $24 \mathrm{~h}$ of ageing.

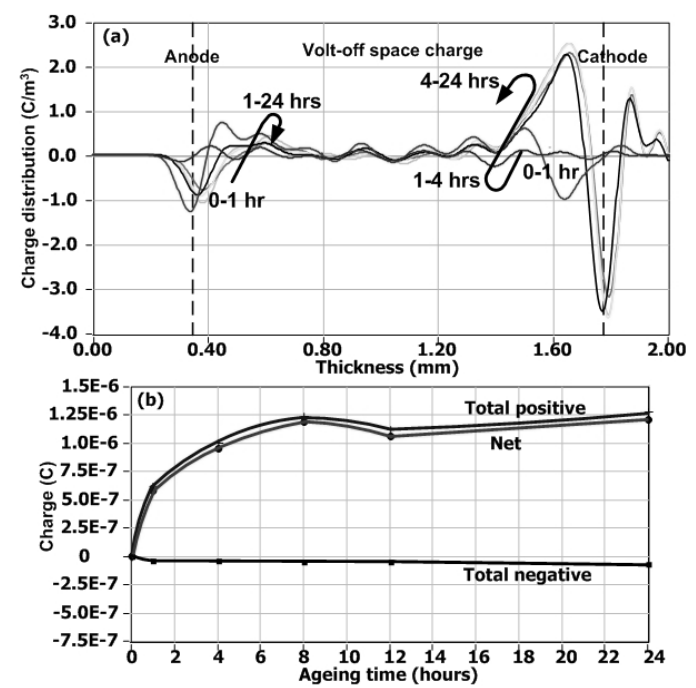

Figure 20. (a) Volt-off space charge profiles and (b) charge integrals of sample $\mathrm{H}$.

At the anode side, however, the trapped charge accumulated during the $1^{\text {st }}$ hour of ageing disappeared after $4 \mathrm{~h}$. This effect was not seen in samples $E$ to $G$, in which positive charge trapped adjacent to the anode remained relatively constant after 4 hours of ageing.

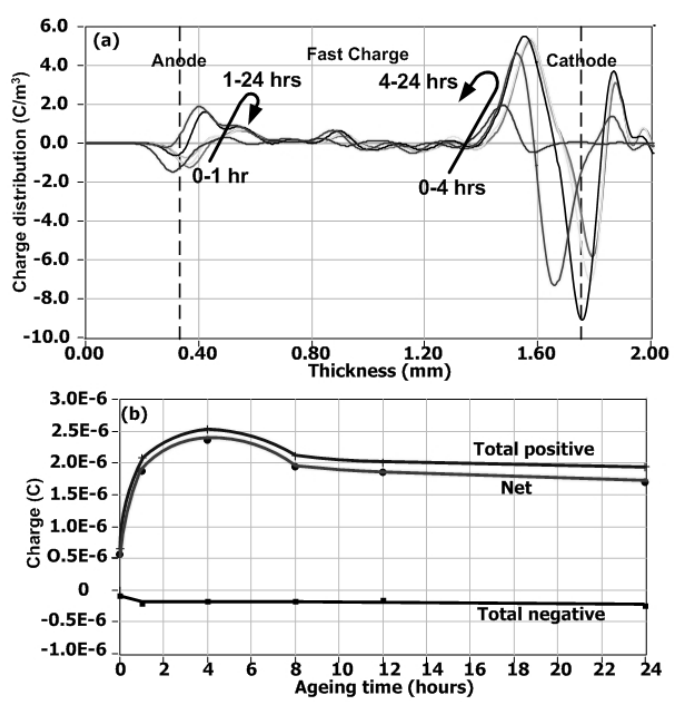

Figure 21. (a) Fast charge profiles and (b) charge integrals of sample H.

As mentioned earlier, there is no trapped charge in the sample at 0 hour. Hence, the drop in the interfacial stress seen 
in the step voltage test must be due to fast charge. A quick look at Figure 21, which shows the fast charge profiles and integrals, confirms the presence of positive fast charge adjacent to both electrodes. This is probably because of the higher energy and mobility of the charge due to the higher testing temperatures, making it difficult for charge to be trapped and remain trapped after the removal of the voltage.

The amount of positive fast charge in the sample rose sharply during the first 4 hours. A slight decrease in the positive charge adjacent to the cathode can be observed after 8 hours of ageing. On the other hand, the positive charge close to the anode has almost completely disappeared by that time. Since the reduction at the cathode side is small as compared to that at the anode side and considering the increase in charge mobility due to high temperature, it is believed that the reduction of positive fast charge is due to negative charge injected from the cathode and transported across the sample since the reduction at the cathode end is small as compared to that at the anode.

It is worth noting that the fast charge profiles of all the degassed samples tested followed similar trend, in that there is an initial increase in the amount of charge followed by a gradual decrease as ageing progressed. This effect was also seen in all the as-received samples tested. As mentioned before, this is believed to be caused by electrical ageing of the XLPE material which resulted in formation of deep traps being accompanied by reduction of shallow ones as a result of dc ageing

A few general remarks can be made when comparing the space charge results of as-received and degassed samples. Firstly, in the case of as-received samples, the amount of trapped charge reduces with time but not in the case of degassed samples. In fact, in the case of degassed sample, the general shape of the space charge distribution changed significantly with testing temperature.

Secondly, space charge distributions of both as-received and degassed samples of at high temperature $\left(70{ }^{\circ} \mathrm{C}\right.$ and above) took the same general form, although the concentration is smaller in the latter.

Lastly, it can be seen from the results of the above study that positive charge propagation enhances as testing temperature increases for both as-received and degassed samples. This should be taken seriously by researchers and cable manufacturers as many studies have shown a direct relationship between positive charge propagation and the intrinsic breakdown of the insulating materials $[5,44]$.

\section{CONCLUSIONS}

In this study, the space charge dynamics in XLPE plaques at different temperatures during $24 \mathrm{~h}$ of dc electric ageing have been reported.

The dc threshold stresses of the as-received and degassed samples are greatly affected by testing temperatures. The testing temperature has numerous effects on space charge dynamics such as reduces the threshold stress at which space charge initiates, enhances ionic dissociation of polar crosslinked by-products, enhances charge injection from the electrodes and increase energy of charge which in turn enhances charge mobility and conductivity.

The amount of trapped charge in the samples decreases while the fast charge increases with testing temperature. This is believed to be due to the increase in energy of the charge, enabling it to be more easily de-trapped.

At temperatures of $70{ }^{\circ} \mathrm{C}$ and above, the space charge distribution takes the same form, albeit lesser in quantity in degassed sample, regardless of whether the sample is degassed or not.

Positive charge propagation enhances as testing temperature increases for both as-received and degassed samples. This can be a major cause of concern as such behavior is usually related to insulation breakdown.

\section{REFERENCES}

[1] K. Bambery and R. Fleming, "The temperature dependence of space charge accumulation in crosslinked polyethylene", IEEE Intern. Sympos. Electrets, pp. 16-21, 1996.

[2] L. Boudou, V. Griseri, I. Guastavino, and L.A. Dissado, "Effect of temperature on space charge formation in low density polyethylene role of antioxidant", IEEE Intern. Conf. Solid Dielectrics, pp. 252-225, 2004.

[3] M. Fu and G. Chen, "Space charge measurement in xlpe cable with temperature gradient through the insulation", IEEE Conf. Electr. Insul. Dielectr. Phenomena, pp. 217-220, 2003.

[4] M. Fu and G. Chen, "The effect of voltage reversal and elevated temperature on space charge behaviour in xlpe cable", Jicables, pp. 491495, 2003.

[5] M. Fukuma, M. Wadamori, M. Nagao, M. Kosaki, K. Fukunaga, and T. Maeno, "Short interval space charge and external circuit current measurements in ldpe film in high temperature region", IEEE Intern. Sympos. Electr. Insul., pp. 497-500, 2001.

[6] Y.F.F. Ho, Y.L. Chong, and G. Chen, "Temperature effect on the space charge characteristics in as-received and degassed xlpe insulation under dc electric sressing conditions", IEEE Conf. Electr. Insul. Dielectr. Phenomena, pp. 241-244, 2003.

[7] T. Kanno, T. Uozumi, and Y. Inoue, "Measurement of space charge distribution in xlpe cable insulation at high temperature", IEEE Intern. Sympos. Electr. Insul., pp. 85-88, 1998.

[8] P. Laurenceau, G. Dreyfus, and J. Lewiner, "New principle for the determination of potential distribution in dielectrics", Phys. Rev. Letts., Vol. 38, pp. 46-49, 1977.

[9] C. Alquie, G. Charpak, and J. Lewiner, "Pulsed laser determination of surface electric charge distributions", J. Physique Letts., Vol. 43, pp. 687-693, 1982 .

[10] C. Alquie, G. Dreyfus, and J. Lewiner, "Stress-wave probing of electric field distribution in dielectrics", Phys. Rev. Letts., Vol 47, pp. 14831487, 1981.

[11] G.M. Sessler, J.E. West, and G. Gerhard, "High-resolution laser-pulse method for measuring charge distributions in dielectrics", Phys. Rev. Letts., Vol 48, pp. 563-566, 1982.

[12] G.M. Sessler, J.E. West, R.G. Multhaupt, and H. Von Seggern, "Nondestructive laser method for measuring charge profiles in irradiated polymer films", IEEE Trans. Nuclear Sci., Vol. 29, pp. 1644-1649, 1982.

[13] C. Alquie, J. Lewiner, and G. Dreyfus, "Analysis of laser induced acoustic pulse probing of charge distributions in dielectrics", J. De Physique Letts., Vol. 44, pp. 171-178, 1983.

[14]R.G. Multhaupt, "Analysis of pressure-wave methods for the nondestructive determination of spatial charge or field distributions in dielectrics", Phys. Rev. B, Vol. 27, pp. 2494-2503, 1983.

[15] J. Lewiner, "Evolution of experimental techniques for the study of the electrical properties of insulating materials", IEEE Trans. Electr. Insul., Vol. 21, pp. 351-360, 1986. 
[16] J. Lewiner, "Direct determination of space charge distributions in dielectrics: The pressure wave propagation method", IEEE Intern. Conf. Conduction and Breakdown in Solid Dielectrics, pp. 548$554,1989$.

[17] F.N. Lim and R.J. Fleming, "The temperature dependence of space charge accumulation and dc current in xlpe power cable insulation", IEEE Conf. Electr. Insul. Dielectr. Phenomena (CEIDP), pp. 66-69, 1999.

[18] J. Holboll, M. Henriksen, and J. Hjerrild, "Space charge build-up in xlpe-cable with temperature gradient", IEEE Conf. Electr. Insul. Dielectr. Phenomena (CEIDP),

[19] C. Alquie, T. Ditchi, and J. Lewiner, "Measurement of charge distribution in insulating materials for high voltage cables", IEEE Intern. Conf. Properties and Applications of Dielectric Materials, pp. 434-437, 1988.

[20] A.E. Davies, G. Chen, X. Wu, R.N. Hampton, S.J. Sutton, and S.G. Swingler, "Calculation of space charge density and electric stress in xlpe compounds", Jicables, pp. 728-732, 1999.

[21] Y.L. Chong, Y.F.F. Ho, and G. Chen, "Automation of space charge measurement by using lipp technique", Intern. Conf. Insulation Condition Monitoring of Electrical Plant, pp. 168-171, 2003.

[22] Y.F.F. Ho, Y.L. Chong, and G. Chen, "Optimization of the aluminum target thickness on the space charge measuremet using lipp technique", IEEE Conf. Electr. Insul. Dielectr. Phenomena (CEIDP), pp. 237-240, 2003.

[23] Y.L. Chong, G. Chen, I.L. Hosier, A.S. Vaughan, and Y.F.F. Ho, "Heat treatment of cross-linked polyethylene and its effect on morphology and space charge evolution", IEEE Trans. Dielectr. Electr. Insul., Vol. 12. pp. 1209 - 1221, 2005.

[24] N. Hirai, Y. Maeno, T. Tanaka, Y. Ohki, M. Okashita, and T. Maeno, "Effect of crosslinking on space charge formation in crosslinked polyethylene", IEEE Intern. Conf. Properties and Applications of Dielectric Materials, pp. 917-920, 2003.

[25] W.S. Lau and G. Chen, "The influence of temperature on electrical conduction and space charge in ldpe", Jicables, pp. 485-490, 2003.

[26] G. Mazzanti, G.C. Montanari, and J. Alison, "A space-charge based method for estimation of apparent mobility and trap depth as markers for insulation degradation - theoretical basis and experimental validation", IEEE Trans. Dielectr. Electr. Insul., Vol. 6, pp. 187-197, 2003.

[27] G. Mazzanti, G.C. Montanari, and F. Palmieri, "Quantities extracted from space-charge measurements as markers for insulation ageing", IEEE Trans. Dielectr. Electr. Insul., Vol. 10, pp. 108-203, 2003.

[28] G.C. Montanari and D. Fabiani, "Examination of dc insulation performance based on space charge measurement and accelerated life tests", IEEE Trans. Dielectr. Electr. Insul., Vol. 6, pp. 322$328,2000$.

[29] Y.L. Chong, H. Miyake, Y. Tanaka, T. Takada, H. Nakama, and G. Chen, "Space charge in polyethylene under ac electric stress using the pulsed eletroacoustic method", IEEE. Conf. Electr. Insul. Dielectr. Phenomena (CEIDP), pp. 77-80, 2004.

[30] G. Chen, M. Fu, X.Z. Liu, and L.S. Zhong, "Ac ageing and space charge characteristics in low density polyethylene polymeric insulation", J. Appl. Phys., Vol. 97, 083713, 2005.

[31] M. Fu, G. Chen, and X.Z. Liu, "Space charge behaviour in ldpe afer ac ageing", IEEE Intern. Conf. Solid Dielectrics, pp. 217-220, 2004.

[32] Y.L. Chong, G. Chen, H. Miyake, Y. Tanaka, and T. Takada, "Effect of ac ageing on space charge evolution in xlpe", IEEE Conf. Electr. Insul. Dielectr. Phenomena, pp. 81-84, 2004.

[33] Y.L. Chong, G. Chen, and Y.F.F. Ho, "Effect of the length of degassing period on the space charge dynamics in xlpe insulation under dc stressing condition", IEEE Intern. Conf. Solid Dielectrics, pp. 162-165, 2004.

[34] S. Mitusmoto, M. Nagao, and M. Kosaki, "Effect of acetophenone on high-field electrical properties in polyethylene", IEEE Conf. Electr. Insul. Dielectr. Phenomena (CEIDP), pp. 157-160, 1996.

[35] S. Mitusmoto, M. Nagao, and M. Kosaki, "High field conduction and space charge distribution in acetophenone-coated polyethylene film", IEEE Intern. Conf. Properties and Applications of Dielectric Materials, pp. 806-809, 1997.
[36] T. Doi, Y. Tanaka, and T. Takada, "Measurement of space charge distribution in acetophenone coated low-density polyethylene", IEEE Conf. Electr. Insul. Dielectr. Phenomena (CEIDP), pp. 32$35,1997$.

[37] N. Nibbio, T. Uozumi, N. Yasuda, and T. Fukui, "The effect of additives on space charge in xlpe insulation", IEEE Intern. Sympos. Electr. Insul. (ISEI), pp. 559-562, 1994.

[38] K. Kobayashi, T. Ohara, Y. Ohki, and T. Maeno, "Effect of acetophenone on the space charge evolution in ldpe and lldpe", IEEE Conf. Electr. Insul. Dielectr. Phenomena (CEIDP), pp. 27$31,1999$.

[39] T. Tsurimoto, S. Mitsumoto, M. Nagao, and M. Kosaki, "Effect of acetophenone on electric conduction in ldpe film", IEEE Intern. Sympos. Electr. Insul. Materials, pp. 267-270, 1995.

[40] T. Fukuda, S. Irie, Y. Asada, M. Maeda, H. Nakagawa, and N. Yamada, "The effect of morphology on the impulse voltage", IEEE Trans. Electr. Insul., Vol. 17, pp. 386-391, 1982.

[41] N. Hirai, Y. Maeno, T. Tanaka, and Y. Ohki, "Roles of cumyl alcohol and crosslinked structure in homo-charge trapping in crosslinked polyethylene", IEEE Intern. Conf. Electr. Insul. Dielectr. Phenomena (CEIDP), pp. 213-216, 2003.

[42] Y. Sekii, T. Kogure, and T. Maeno, "Influence of physical properties and peroxide decomposition products on the space charge formation in xlpe and epdm", IEEE Intern. Conf. Properties and Applications of Dielectr. Materials, pp. 132-136, 1997.

[43]R. Fleming, "Space charge in polymers, particularly polyethylene", Brazilian J. Phys., Vol. 29, pp. 280-294, 1999.

[44] K. Matsui, Y. Tanaka, T. Takada, and T. Maeno, "Space charge observation in various types of polyethylene under ultra-high dc electric field", IEEE Intern. Conf. Solid Dielectr., pp. 201-204, 2004.

Yeng Leong Chong obtained the B.Eng. degree from the University of

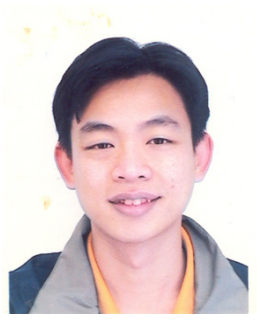
Southampton in 2001. He started the Ph.D. course in 2002, researching in space charge and degradation of polyethylene in the Tony Davies High Voltage Laboratory in the same university. His other research interests include signal processing and system automation. He graduated in 2005 and has since returned to his home country in Singapore.

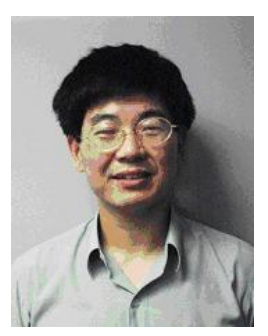

George Chen was born in China in 1961. He received the B.Eng. degree in 1983 and the MSc degree in 1986 in electrical engineering from Xian Jiaotong University, China. After he obtained the Ph.D. degree in 1990 from the University of Strathclyde, UK, on the work of permanent changes in electrical properties of irradiated low-density polyethylene, he joined the University of Southampton as postdoctoral research fellow and became senior research fellow subsequently. In 1997 he was appointed as a research lecturer and promoted to a Reader in 2002. Over the years, he has developed a wide range of interests in high voltage engineering and electrical properties of materials and has published over 100 papers. 